\title{
Medical Waste Management: A Case Study of the Souss-Massa-Drâa Region, Morocco
}

\author{
Adnane Mbarki*, Belkacem Kabbachi, Abdelkarim Ezaidi, Mohamed Benssaou \\ Environmental Sciences and Geoscience Department, Faculty of Sciences, University Ibn Zohr, Agadir, Morocco. \\ Email: *adnanembarki@hotmail.com
}

Received June $15^{\text {th }}$, 2013; revised July $19^{\text {th }}, 2013$; accepted August $12^{\text {th }}, 2013$

Copyright (C 2013 Adnane Mbarki et al. This is an open access article distributed under the Creative Commons Attribution License, which permits unrestricted use, distribution, and reproduction in any medium, provided the original work is properly cited.

\begin{abstract}
Medical waste management is of major concern due to the potentially high risks to both human health and the environment caused by inadequate waste management practices. In Morocco, as in many developing countries, little information is available regarding generation handling, and disposal of medical waste. The specific objective of this study was to analyse the medical waste management practices in the Souss-Massa-Drâa region, Morocco. The study was carried out in seven of the twelve hospitals in the region, covering $66.2 \%$ of the bed capacity. A total of 219 healthcare personnel and their assistants were included: 35 doctors, 98 nurses, and 86 housekeepers. Site visits, interviews, and survey questionnaires were implemented to collect information regarding different medical waste management aspects, including medical waste generation, separation, collection, storage, transportation, and disposal. The results indicated that the medical waste generation rate ranged from 0.4 to $0.7 \mathrm{Kg} / \mathrm{bed}$-day with a weighted average of $0.53 \mathrm{Kg} / \mathrm{bed}$-day. The percentage of infectious and hazardous wastes in the total medical waste stream was about $30.5 \%$. The remaining $69.5 \%$ was general wastes similar in properties to municipal wastes. Concerning waste separation, housekeepers demonstrate a slightly higher knowledge about waste separation, with $49.4 \%$ of correct answers, with nurses at $45.7 \%$, and doctors the lowest value at $38.6 \%$. The results about other management aspects indicated that practices in most surveyed hospitals did not comply with the principles stated in Moroccan legislation. Based on the findings, some measures are suggested to improve the present conditions and ensure that potential health and environmental risks of medical waste are minimized.
\end{abstract}

Keywords: Environment; Health; Healthcare Personnel; Medical Waste; Morocco

\section{Introduction}

Medical wastes are of substantial importance due to their potential as environmental hazards and their risks to human health. This type of waste contains infectious waste, toxic chemicals and heavy metals, and may contain substances that are genotoxic or radioactive. Despite the fact that current medical waste management practices vary from hospital to hospital, the problematic areas are similar for all healthcare units and at all stages of management [1]. World Health Organization (WHO) in 2002 conducted an investigation survey on management of medical waste in 22 developing countries. Results showed that the proportion of healthcare facilities that did not use proper waste disposal methods ranged from $18 \%$ to $64 \%$ [2]. Improper management practice impacts both directly and/or indirectly the healthcare staffs, patients

\footnotetext{
"Corresponding author.
}

and hospital environment [3,4]. It is of great importance to manage medical waste in a proper manner to avoid risks to both human health and the environment.

Good medical waste management in a hospital depends on a dedicated waste management team, good administration, careful planning, sound organization, underpinning legislation, adequate financing, and full participation by trained staff [5]. In addition some authors indicated the importance of other aspects, including the use of appropriate techniques for disposal [6,7], an internal management system and training program for related personnel [8,9], the waste generated [1], and a national regularly framework $[10,11]$. The medical waste management practice in Morocco is performed in accordance with the Medical Waste Management Decree No. 2-09139 of 2009 [12]. Decree No. 2-09-139 establishes definitions, principles and the procedures for separation, collection, transportation, storage and disposal of medical 
waste. The medical wastes have been defined as any solid waste that results from the treatment, diagnosis, or immunization of humans and/or animals at hospitals, veterinary and health-related research facilities, and medical laboratories. Decree No. 2-09-139 also attributes specific responsibilities to the various sectors involved: generators, sanitation and environment. The Decree states that generators are mandated to properly manage medical waste.

In order to improve medical waste management and develop a management strategy for the Souss-MassaDrâa region, it is important to understand and evaluate current practices in medical waste management. Information regarding medical waste management in this region is currently insufficient. The main objective of this study is to assess the current management practices of medical waste in hospitals of the Souss-Massa-Drâa region. Medical waste management was surveyed by gathering information regarding medical waste generation, separation, collection, storage, transportation, and disposal. Additionally, some measures are suggested to improve the present conditions and solve the identified problems.

\section{Materials \& Methods}

This study was performed from September 2012 to January 2013, in seven of the twelve hospitals in the SoussMassa-Drâa region, Morocco. The seven hospitals contain 1548 beds, corresponding to 66.2\% of the region's total bed capacity. The studied hospitals provide general medical, surgical, pediatric, maternity, and a range of specialist services.

Site visits, interviews, and survey questionnaires were implemented to collect information regarding different medical waste management aspects, including medical waste generation, separation, collection, storage, transportation, and disposal. During site visits, observation checklists were used based on Moroccan legislation and guided by the literature [13-18]. To support and supplement information collected during site visits, interviews were conducted with the managers responsible for environmental management, and the personnel involved in the collection and handling of medical wastes in each hospital.

The questionnaires were formulated to evaluate the knowledge and waste management practices of doctors, nurses, and housekeepers. Questionnaires were distributed to various departments in each hospital. Confidentiality was ensured and all forms were anonymous. The questionnaires involved 25 items that covered areas of medical waste management. At the end of this survey, 219 questionnaires were valid (the response rate was $75.5 \%$ ). Data from the questionnaires were stored and coded in a database for subsequent analysis. The data were checked for consistency and completeness, and then statistically analysed using Epi-info Software.

\section{Results and Discussion}

In order to develop proper waste management strategies, it is important to have accurate information on the medical waste generation rate. Results from the survey suggested that the average generation rate of medical waste produced at the seven hospitals is between 0.4 and 0.7 $\mathrm{Kg} / \mathrm{bed}$-day with a weighted average of $0.53 \mathrm{Kg} / \mathrm{bed}$-day. These results were compared with generation rates determined in other studies from different countries. In the study performed in the Sylhet city in Bangladesh, the average generation rate of medical wastes was about $0.934 \mathrm{Kg} /$ bed-day [19]. A study conducted by Abdulla et al. (2008) indicated that the weighted average generation rate was $0.83 \mathrm{Kg} /$ bed-day in northern Jordan. Abd ElSalam (2010) reported an average generation in El-Beheira Governorate, Egypt, of about 2.07 Kg/bed-day [20]. Birpinar et al. (2008) investigated 192 hospitals in Istanbul, Turkey, and reported an average generation rate of $0.63 \mathrm{Kg} /$ bed-day [21]. Finally, Ruoyan et al. (2010) reported an average generation in Binzhou District, China, of about $1.22 \mathrm{Kg}$ /bed-day [22]. The Souss-MassaDrâa region has a much lower medical waste generation rate as compared to these regions. The difference may be due to living habitudes and standards, availability of treatment facilities and also ways to categorizing wastes. Marincovic et al. (2008) reported that the medical waste generation rate depends on the size and the type of the medical institution, but also that it differs from country to country based on the level of economic development [23]. Furthermore, the use of disposable instruments and packaging materials rather than the use of reusable items in the healthcare centres in developed countries has increased the amount waste generation.

One important component of a waste characterization program involves the determination of the composition of the wastes. A sound understanding of the contents of the waste stream is helpful in the development of realistic waste reduction and recycling programs. According to the survey, it was found that around $69.5 \%$ of medical wastes was general wastes similar in properties to municipal wastes. The remaining 30.5\% was infectious and hazardous wastes. The percentage distribution of the composition of the medical wastes are presented at Figure 1: $69.5 \%$ is municipal, $10.6 \%$ is pharmaceutical and cytotoxic, $8.3 \%$ is biological, $7.4 \%$ is sharps, and $4.2 \%$ is pathological. Pruss et al., (1999) found that 10\% - 25\% of medical wastes was termed as infectious, pharmaceutical, radioactive and chemical wastes [17]. In France, $15 \%$ - $20 \%$ of medical wastes is infectious-hazardous wastes [24] while in USA around 15\% is considered as infectious and hazardous wastes [25]. According to a 


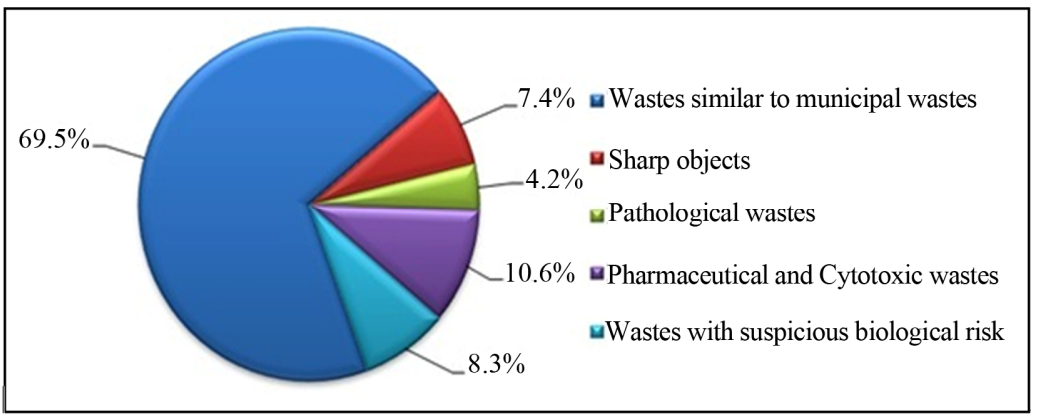

Figure 1. Percentage of the composition of medical wastes.

summary by Diaz et al. 2008, the total amount of medical waste generated in selected hospitals in developing countries varied from 0.016 to $3.23 \mathrm{Kg}$ /bed-day and the percentage of infectious-hazardous waste in the total medical waste stream in developing countries was about 63\% (From 0.01 to $0.65 \mathrm{Kg} /$ bed-day) [26].

Waste generation source quantity and quality of waste generation are the key issues to decide an effective medical waste management practice. Therefore, it is important to minimize waste generation rate at each generation source. On this basis, appropriate medical waste separation at generation source can be an effective solution.

In the studied hospitals, medical waste separation is performed according to the types defined in Moroccan legislation (Table 1). Results from the questionnaires indicate that the knowledge of healthcare staff related to medical waste separation is generally low (Table 2). Housekeepers demonstrate a slightly higher knowledge about waste separation, with $49.4 \%$ of correct answers, with nurses at $45.7 \%$, and doctors the lowest value at $38.6 \%$. The highest percentage of satisfactory knowledge is related to municipal wastes, but more uncertainly occurs in pharmaceutical and cytotoxic wastes for all healthcare staff (Table 2).

These results are probably related to the level of daily waste contact; housekeepers and nurses are the healthcare staff groups with the highest levels of daily contact with medical wastes (76.7\% of housekeepers and $67.1 \%$ of nurses). Doctors show the lower daily contact, with only $29.2 \%$ indicating such contact with medical wastes.

The different levels of knowledge about waste separation between healthcare staff groups may also reflect specific training concerning waste; housekeepers have the highest participation rates in training programs related to medical waste risks (80.8\%), and doctors have the lowest participation (31.5\%). About $70.8 \%$ of the nurses participated in these programs. Hence, the WHO advised that proper training and education must be offered to all workers from doctors to ward personnel, and most healthcare workers require the same basic set of skills, information and attitudes towards good waste
Table 1. Separation of medical wastes according to Moroccan legislation.

\begin{tabular}{cc}
\hline Waste type & Separation \\
\hline Wastes with suspicious biological risk & Red bags \\
Sharp objects & Yellow boxes \\
Pharmaceutical and cytotoxic wastes & Brown bags \\
Pathological wastes & White boxes \\
Wastes similar to municipal wastes & Black bags \\
\hline
\end{tabular}

Table 2. Correct answers concerning waste separation procedures by healthcare staff.

\begin{tabular}{|c|c|c|c|c|c|c|}
\hline \multirow{2}{*}{ Waste type } & \multicolumn{2}{|c|}{ Doctors } & \multicolumn{2}{|c|}{ Nurses } & \multicolumn{2}{|c|}{ Housekeepers } \\
\hline & $\mathrm{N}^{\circ}$ & $\%$ & $\mathrm{~N}^{\circ}$ & $\%$ & $\mathrm{~N}^{\circ}$ & $\%$ \\
\hline $\begin{array}{l}\text { Wastes with } \\
\text { biological risk }\end{array}$ & 20 & 28.5 & 83 & 42.3 & 92 & 53.5 \\
\hline Sharp objects & 24 & 34.3 & 87 & 44.4 & 79 & 45.9 \\
\hline $\begin{array}{l}\text { Pharmaceutical and } \\
\text { cytotoxic }\end{array}$ & 13 & 18.5 & 61 & 31.1 & 43 & 25.0 \\
\hline Pathological wastes & 27 & 38.5 & 91 & 46.4 & 84 & 48.8 \\
\hline Municipal wastes & 51 & 72.8 & 126 & 64.3 & 127 & 73.8 \\
\hline Total & 135 & 38.6 & 448 & 45.7 & 425 & 49.4 \\
\hline
\end{tabular}

management [5]. If training is conducted on the job, it should help reinforce good practice and teamwork. Moreover, periodic repetition of courses will provide refresher training as well as orientation for new employees with new responsibilities; it will also update knowledge in line with policy changes $[27,28]$.

Inadequate knowledge of waste separation as revealed in the survey is also shown with respect to knowledge of which coloured bag should be used for particular wastes (Table 3).

This inadequate waste separation will lead to inadequate treatment and final disposal of wastes, and could provide risks to healthcare workers, to the environment, and to human health. Results regarding the separation of pharmaceutical and cytotoxic wastes show that slightly 
Table 3. Inadequate waste separation and frequency of incorrect answers.

\begin{tabular}{cccc}
\hline Waste type & $\begin{array}{c}\text { Inadequate answers } \\
\text { to separation }\end{array}$ & \multicolumn{2}{c}{$\begin{array}{c}\text { Frequency } \\
\%\end{array}$} \\
\hline $\begin{array}{c}\text { Pharmaceutical } \\
\text { and cytotoxic wastes }\end{array}$ & Red bags & 44.7 & 73.5 \\
Black bags & 28.8 & \\
Wastes with suspicious & Brown bags & 25.5 & \\
biological risk & Black bags & 16.9 & 42.4 \\
$\begin{array}{c}\text { Wastes similar to municipal } \\
\text { wastes }\end{array}$ & Red bags & 7.7 & \\
\hline
\end{tabular}

less than three-fourths of healthcare staff (73.5\%) responded incorrectly by identifying red or black bags. The adequate treatment specified in legislation for pharmaceutical and cytotoxic wastes is incineration and these materials should be collected in brown bags. However, pharmaceuticals and cytotoxics are stored by $44.7 \%$ of staff into red bags, which will lead to an autoclave of these wastes. This pre-treatment of such wastes is not suitable and could result in workers being exposed to volatile compounds between treatment cycles [29]. Some pharmaceutical and cytotoxic wastes are also erroneously collected in black bags (28.8\%) and, as such, are considered to municipal wastes and sent to non-hazardous landfill. This could lead to the contamination of soil and water resources [17]. In addition, $25.5 \%$ of the suspicious biological risk wastes are incinerated because they are placed by healthcare staff in brown bag. This practice results in higher emission of pollutants [30] and greater treatment costs [1].

After the medical wastes are separated, workers should collect them and move them from the location of generation to temporary storage areas, based on the current regulations. From checklists and site visits, it had been observed that the management of medical wastes had not been conducted properly (Table 4); only two hospitals (28.6\%) use appropriate equipment for their collection personnel.

As the Medical Waste Management Decree No. 2-09-139 outlined, workers are required to wear appropriate uniforms and protective equipment when collecting medical waste. It is important for workers to know and understand the potential risks associate with medical wastes, and the importance of consistent use of personnel protection [31]. In addition, only three hospitals (42.8\%) had well sanitized their temporary storage areas. According to Pruss et al. (1999), the temporary storage location, storage containers and storage management have a direct impact on the resulting environmental and the health risks at the hospitals, which must be well sanitized, secured for access only to authorized personnel [17].
Table 4. Assessment of medical waste management practices in the studied hospitals $(\mathrm{N}=7)$.

\begin{tabular}{|c|c|c|}
\hline & $\mathrm{N}$ & $\%$ \\
\hline \multicolumn{3}{|l|}{ Collection } \\
\hline $\begin{array}{l}\text { Workers wear protective equipment } \\
\text { when collecting medical waste }\end{array}$ & 2 & 28.6 \\
\hline $\begin{array}{l}\text { There are defined procedures for collecting } \\
\text { waste from specific units in the hospital }\end{array}$ & 5 & 71.4 \\
\hline \multicolumn{3}{|l|}{ Storage } \\
\hline There is a temporary storage within the hospital & 5 & 71.4 \\
\hline The temporary storage areas are sanitized & 3 & 42.8 \\
\hline There is special place for hazardous waste storage & 5 & 71.4 \\
\hline \multicolumn{3}{|l|}{ Transportation } \\
\hline Wastes are transported in suitable bags or containers & 4 & 57.1 \\
\hline $\begin{array}{c}\text { There are defined routes for transportation } \\
\text { of waste within the hospital }\end{array}$ & 5 & 71.4 \\
\hline \multicolumn{3}{|l|}{ Disposal } \\
\hline $\begin{array}{l}\text { There is a location of medical } \\
\text { waste disposal site in the hospital }\end{array}$ & 1 & 14.3 \\
\hline There is a company responsible for the final disposal & 6 & 85.7 \\
\hline
\end{tabular}

Furthermore, four hospitals (57.1\%) have appropriate bags for the collection of medical wastes. Although the original waste bags should be resistant to be punctures during transportation, in order to reduce the cost, most of the plastic bags manufactured do not comply with this requirement. When punctured, these bags are torn and their contents which may be infectious and hazardous can be spread into the container and vehicle, and to the environment. Besides, most of the waste bags used are not marked indicating they contain medical wastes. Because of the absence of appropriate labelling, it is difficult for the public and workers to identify the source and the type of medical waste. Another problem faced is the high disposal costs of medical wastes in all surveyed hospitals. Because the quantity is low, there are no economies of scale and the disposal cost is high.

\section{Conclusions}

The number of hospitals in the Souss-Massa-Drâa region, Morocco, is constantly increasing. This leads to an increase in the quantity of medical waste generated. Although the Ministry of Health together with the Ministry of Environment has developed regulations aimed to ensure appropriate handling and processing of medical waste, there is still need to put the regulations into practice.

The medical waste management situation in the region, while far from ideal, is better than in other parts of Morocco. To ensure improvement and continuity in the management practices, hospitals need to be integrated into 
routine employee training, continuing education, and management evaluation processes for systems and personnel. They should provide secure methods of the medical waste collection and handling. The final goal is a system that is in harmony with sustainable development and protects the environment and human health.

\section{Acknowledgements}

The authors would like to thank the personnel of the studied hospitals, for their assistance in conducting this study.

\section{REFERENCES}

[1] M. Tsakona, E. Anagnostopoulou and E. Gidarakos, "Hospital Waste Management and Toxicity Evaluation: A Case Study,” Waste Management, Vol. 27, No. 7, 2007, pp. 912-920. doi:10.1016/j.wasman.2006.04.019

[2] WHO, "Safe Healthcare Waste Management: Policy Paper,” World Health Organization, Geneva, 2004.

[3] M. A. Patwary, W. T. O’Hare, G. Street, K. M. Elahi, S. S. Hossain and M. H. Sarke, "Country Report: Quantitative Assessment of Medical Waste Generation in the Capital City of Bangladesh,” Waste Management, Vol. 29, No. 8, 2009, pp. 2392-2397. doi:10.1016/j.wasman.2009.03.021

[4] S. A. Tamplin, D. Davidson, B. Powis and Z. O'Leary, "Issues and Option for the Safe Destruction and Disposal of Used Injection Materials,” Waste Management, Vol. 25, No. 6, 2005, pp. 655-665.

doi:10.1016/j.wasman.2004.07.007

[5] WHO, "Healthcare Waste Management," World Health Organization, Geneva, 2005.

[6] B. K. Lee, M. J. Ellenbecker and R. Moure-Eraso, “Alternatives for Treatment and Disposal Cost Reduction of Regulated Medical Waste,” Waste Management, Vol. 24, No. 2, 2004, pp. 143-151. doi:10.1016/j.wasman.2003.10.008

[7] L. F. Diaz, G. M. Savage and L. L. Eggerth, “Alternatives for the Treatment and Disposal of Healthcare Wastes in Developing Countries,” Waste Management, Vol. 25, No. 6, 2005, pp. 626-637. doi:10.1016/j.wasman.2005.01.005

[8] C. E. Silva, A. E. Hoppe, M. M. Ravanello and N. Mello, "Medical Wastes Management in the South of Brazil," Waste Management, Vol. 25, No. 6, 2005, pp. 600-605. doi:10.1016/j.wasman.2004.03.002

[9] F. Abdulla, H. A. Qdais and A. Rabi, "Site Investigation on Medical Waste Management Practices in Northern Jordan,” Waste Management, Vol. 28, No. 2, 2008, pp. 450458. doi:10.1016/j.wasman.2007.02.035

[10] M. Askarian, M. Vakili and G. Kabir, "Results of Hospital Waste Survey in Private Hospitals in Fars Province, Iran,” Waste Management, Vol. 24, No. 4, 2004, pp. 347352. doi:10.1016/j.wasman.2003.09.008

[11] E. Shinee, E. Gombojav, A. Nishimura, N. Hamajima and K. Ito, "Healthcare Waste Management in the Capital City of Mongolia,” Waste Management, Vol. 28, No. 2,
2008, pp. 435-441. doi:10.1016/j.wasman.2006.12.022

[12] Ministry of Health, "Handbook of Medical Waste," MOH, Kingdom of Morocco, 2010, pp. 35-44.

[13] W. H. Bassett, "Clays Handbook of Environmental Health, 16th Edition, Chapman \& Hall Medical, London, 1992, pp. 615-656.

[14] MOHP, "Handbook of Hazardous Health Care Waste Management,” Ministry of Health and Population, Bangkok, 1995, pp. 54-86.

[15] Centers for Disease Control and Prevention, "Guidelines for Protecting the Health and Safety of Health Care Workers,” CDC, Atlanta, 1998. pp. 88-119.

[16] E. Cole, "Health Care Waste Management within Hospitals,” 3rd Edition, C.V. Mosby, St Louis, Baltimore, 1998. pp. 168-247.

[17] A. Pruss, E. Giroult and P. Rushbrook, "Safe Management of Wastes from Healthcare Activities," World Health Organization, Geneva, 1999.

[18] World Health Organization, "Safe Management of Waste from Health Care Activities,” Western Pacific Regional Office Preparedness, WHO, Geneva, 2003, pp. 58-64.

[19] M. S. Kaiser Alam Sarkar, M. A. Haque and T. A. Khan, "Hospital Waste Management in Sylhet City," ARPN Journal of Engineering and Applied Sciences, Vol. 1, No. 2, 2006.

[20] M. M. Abd El-Salam, "Hospital Waste Management in El-Baheira Government, Egypt,” Journal of Environmental Management, Vol. 91, No. 3, 2010, pp. 618-629. doi:10.1016/j.jenvman.2009.08.012

[21] M. E. Birpinar, S. B .Mehmet, et al., "Medical Waste Management in Turkey: A Case Study of Istanbul," Waste Ma- nagement, Vol. 29, No. 1, 2009, pp. 445-448. doi:10.1016/j.wasman.2008.03.015

[22] R. Y. Gai, L. Z. Xu, H. J. Li, C. C. Zhou, J. J. He, S. Yoshihisa, W. Tang and K. Chushi, "Investigation of Healthcare Waste Management in Binzhou District, China," Waste Management, Vol. 30, No. 2, 2010, pp. 246-250. doi:10.1016/j.wasman.2008.08.023

[23] N. Marincovic, T. Pavic, K. Vitale, N. J. Holcer and A. Dzakula, "Management of Hazardous Medical Waste in Coatia,” Waste Management, Vol. 28, No. 6, 2008, pp. 1049-1056. doi:10.1016/j.wasman.2007.01.021

[24] L. Galtier and C. Bekaert, "Healthcare Waste Management on an International Scale," Appropriate Environmental and Solid Waste Management and Technologies for Developing Countries, Vol. 1, ISWA 2002, Istanbul, 2002, pp. 289-294.

[25] C. C. Lee and G. L. Huffman, "Medical Waste Management/Incineration,” Journal of Hazardous Materials, Vol. 48, No. 1-3, 1996, pp. 1-30. doi:10.1016/0304-3894(95)00153-0

[26] L. F. Diaz, L. L. Eggerth, Sh. Enkhtsetseg and G. M. Savage, "Characteristics of Healthcare Wastes," Waste Management, Vol. 28, No. 7, 2008, pp. 1219-1226. doi:10.1016/j.wasman.2007.04.010

[27] N. Gardan, "Professional Development, Infection Control, the Role of the Nurse,” Nursing Journal, Vol. 4512, 1991. 
pp. 23-32.

[28] K. Kisliore and O. K. Ingle, "Biomedical Waste Management in India,” Century Publications, New Delhi, 2004, p. 144.

[29] WHO, "Management of Solid Health-Care Waste at Primary Health-Care Centres: A Decision-Making Guide," World Health Organization, Geneva, 2005.
[30] M. Alvim-ferraz and S. Afonso, "Incineration of Healthcare Wastes: Management of Atmospheric Emissions through Waste Segregation,” Waste Management, Vol. 25, No. 6, 2005, pp. 638-648.

doi:10.1016/j.wasman.2004.07.017

[31] A. Coad, Christen and J. March, "How Are We Managing Our Healthcare Waste,” Skat Publisher, Switzerland, 1999. 